\title{
Towards an understanding of Indigenous perspectives through the eyes of pre-service science education students
}

\author{
Gregory Smith \\ School of Education, \\ Charles Darwin University \\ gregory.smith@cdu.edu.au
}

\section{Michael Michie}

Division of Higher Education and Research, Batchelor Institute of Indigenous Tertiary Education

michael.michie@batchelor.edu.au

Keywords: concept maps; Indigenous perspectives; network analysis; local science; pre-service science teachers

\begin{abstract}
This paper presents an analysis of 'Indigenous perspectives' as presented by 150 pre-service teachers of science education. They were presented with an open ended task that required them to choose a concept or topic in school science, and then incorporate their understanding of an Indigenous perspective relative to their chosen science concept. The demonstration of their science concept Indigenous perspective used network visualisation: concept maps or mind maps. Here the connections between Western science knowledge, Indigenous knowledge and knowledge application elements of the visualisations represented student constructed understandings or perceptions.

The concept maps and mind maps were analysed in a staged process. Firstly, grouping of visualisations based on concept representations to uncover themes, and then using Network Theory, each theme was statistically analysed, concluding in an 'all' concept meta-analysis. This analysis was undertaken to mathematically developed models of concepts links. The analysis demonstrated six overlapping and interrelated areas of Western school science themes: seasons and weather, astronomy, plants, animals, use of natural resources, and ecology. The network analysis presented a complex web of interrelated knowledge constructs. This complex web of interrelated knowledge was within and across the six themes. Such findings indicate an Indigenous perspective is a relational construct inclusive of Western science knowledge, Indigenous knowledge and knowledge application. It also reflected the place-based nature of Indigenous knowledge.

This study presents an Indigenous perspective as a complex web of interrelated Western school science and Indigenous knowledges. Such complex representations provide the possibility for a reconceptualisation of Australian science curriculum where science education is an interrelated human endeavour interacting with the natural world and where two worldviews coexist with one informing the other.
\end{abstract}

\section{Introduction}

An Indigenous perspective is a term introduced to school science by the Australian Council of Federal, State and Territory Education Ministers in December 2010. The introduction, fore-grounded in the Shape of Australian Curriculum: Science (National Curriculum Board, 2009) indicated that the Australian science curriculum "will provide opportunities for students to develop understandings of aspects of Indigenous cultures" ( $\mathrm{p} .10)$. This then became the cross-curriculum priority, Aboriginal and Torres Strait Islander histories and cultures (Australian Curriculum, Assessment and Reporting Authority, ACARA, 2011), where school students are required to "develop an understanding that Aboriginal and Torres Strait Islander Peoples have particular ways of knowing the world and continue to be innovative in providing significant contributions to development in science". All Australian states and territories had agreed to implement the Australian Curriculum: Science (ACS) by the end of 2014 (ACARA, 2011). However, there 
have been various levels of curriculum implementation and modification by states and territories. In considering the place of Indigenous perspectives, anecdotal evidence indicates that the implementation is at best superficial, and at worst tokenistic and stereotyped, if at all.

Indigenous perspectives are, in general, presented as a collection of Indigenous understandings that relate to topics that are taught in subjects in the Australian Curriculum, in this case the focus is science. The science in the Australian Curriculum and in this research is defined as western school science. The rhetoric in the Australian Curriculum goes further in the suggestion that Indigenous perspectives are related to Indigenous worldviews or ways of seeing the world. In the science subject area there is an acknowledgment that there are substantial differences between the Western scientific worldviews and Indigenous worldviews (Michie, 2015).

As science educators, this research was designed to gain an understanding of Indigenous perspectives in Western school science using pre-service teacher's perceptions, to better inform our pre-service science education teaching. We recognised the importance of Indigenous knowledge in our university science education curriculum. This point was highlighted in the Review of Australian Higher Education (Bradley, Noonan, Nugent \& Scales, 2008) where they acknowledge the importance of Indigenous knowledge in the 'academy' of university discipline knowledge. The way forward in developing our understanding was to have students present their perceptions by constructing concept or mind maps as one of the unit (subject) assessment items. Subsequently, the concept maps were analysed using a network analysis approach (Borgatti \& Halgin, 2011) to elucidate the emergent relationships and the complexity of the students' understanding.

We acknowledge that perspectives are cultural, so that both Indigenous and science perspectives are steeped in culture (Aikenhead, 2001). We recognise that the focus of our research may suggest a Western neo-colonial view of school science and while this possibility is accepted; the goal of our research was to understand our students' perspectives, so we might modify the pedagogical approach, so as not promote asymmetrical imbalances in the relationships between cultures.

\section{Concept and mind maps}

Concept and mind maps are visualisations that represent relationships between concepts. These relationships are indicated by directional or unidirectional lines linking the concepts (Novak \& Gowin, 1984; Nesbit and Adesope, 2006; Novak \& Cañas, 2007). The relational structure reveals point-in-time perceptions of the constructor, and is therefore unique, as it reflects "his/her experiences, beliefs and biases in addition to his/her understanding of a concept" (Kinchin, Hay \& Adams, 2000, p.44), or in other words a 'mental model'.

Such maps can be considered as part of the wider category of knowledge maps also known as cognitive maps, semantic networks or visual organisers, all of which represent a mental model of the relationships between nodes: concepts (O'Donnell, Dansereau \& Hall, 2002). Our study uses the terms concept and mind map within the broader cognitive map category.

Cañas (2003) points to the use of maps as a technique for eliciting knowledge sectors such as education, government, and business to "reveal expert-novice differences, knowledge elicitation with experts, to support design of new technologies and in software-assisted knowledge acquisition" (p.40). In education, maps have been used as a tool to demonstrate the changes that occur in student conceptual knowledge structures (e.g. from novice to expert, integration of new knowledge into existing cognitive structures). Quantitative scoring methods have been established based on concept map components, validity of links and structures (Novak \& Gowin, 1984), and to describe the comparisons of students' maps to those of experts (Ruiz-Primo \& Shavelson, 1996). Maps constructed by students using a set of predetermined concepts have been used in assessment practices (McPhan, 2008). Maps construction provides beforeafter indicators of cognitive development (Kinchin et al., 2000) where the level of networked complexity demonstrates an increasingly complex of understanding.

Concept and mind maps are used in the context of our study as a tool to disclose the emergent understanding and internal models of pre-service teachers of science. The maps constructed, presented 
and externalised through visualisations of web associations. This adds another category to the list of educational uses above (Novak \& Cañas, 2007), as it focuses on eliciting the individual understandings of novice pre-service teachers of science, and then uses network analysis of the collective perceptions of students' mental models of Indigenous perspectives.

\section{Indigenous perspectives}

The idea of an Indigenous (or Aboriginal ${ }^{1}$ ) perspective in the Australian science curriculum can be traced back formally to the Hobart Declaration (MCEECDYA, 1989). Among the Common and Agreed National Goals for Schooling in Australia was listed: "To provide students with an understanding and respect for our cultural heritage including the particular cultural background of Aboriginal and ethnic groups" (p. 1). This led to the state and territory education authorities setting up positions and committees relating to implementing this goal which became known informally as Indigenous perspectives. The idea of Western school science and the Indigenous culture became a part of what are known as cross-curriculum perspectives, with little consideration of how this goal could be implemented. Subsequently, the Hobart Declaration has been rewritten and renamed twice (as the Adelaide Declaration in 1999, followed by the Melbourne Declaration in 2008) and in both cases the emphasis on Indigenous knowledge has been reinforced (as has participation in the education process of Indigenous students and their parents). One of the cross-curriculum priorities in the overall Australian Curriculum is referred to as Aboriginal and Torres Strait Islander histories and cultures (ACARA, 2011). The curriculum then also included a category to encompass knowledge, skills, behaviours and dispositions called General Capabilities, of which one was Intercultural understanding. These are often combined and are known informally, and continue to be referred to in schools, as Indigenous perspectives. Indigenous perspectives in this context have morphed into a collection of Indigenous knowledge that relates to topics taught in school science. The latest version of the science curriculum speaks only of Aboriginal and Torres Strait Islander histories and cultures as a cross-curriculum priority. Here there is recognition of long standing scientific knowledge traditions and developed knowledge about the world (ACARA v8.2, 2015). The underlying understandings of the Indigenous worldviews or ways of seeing the world - knowing, doing and being seem to be somewhat obscured.

The original rationale for the Indigenous perspectives was to increase non-Indigenous students' and teachers' awareness and knowledge of the Indigenous world (Michie, 2002). This has been expanded to focus on the effective education of Indigenous Australians as well, and is exemplified in the Primary Connections curriculum resource materials which aim to address teaching school science to Indigenous students (Bull, 2008). In Canada, there are examples of Aboriginal perspectives being used in the science education of Aboriginal as well as non-Aboriginal students (Aikenhead et al., 2014). Indigenous perspectives differ from culturally relevant and culturally responsive pedagogies as they are situated within the Western school science curriculum as content rather than pedagogy.

In the past there has been references to relevant Indigenous knowledge in science texts but these were considered to be stereotypical and pejorative (Ninnes, 2000), a situation which needed to be rectified. There also had been continuing discussion about the role of Indigenous knowledge in Western science, with some scientists and philosophers of science considering the two to be incompatible for a variety of reasons (e.g. Matthews, 2009). Other scientists, particularly some African scientists (e.g. in Semali \& Kincheloe, 1999), and groups of science educators interested in cultural studies (Aikenhead \& Ogawa, 2007), have identified the need to bring the two sciences more closely together in both Western science and in school science. The positioning of Western science and Indigenous knowledge has again been awakened through the Inspiring Australia report, Indigenous Engagement with Science: towards a better understanding (Inspiring Australia, 2013), where there is a recognition that "Australia's Indigenous knowledge systems are by their very nature complex holistic and interdisciplinary systems that cannot be viewed merely as potential subsets of Australia's Western knowledge system" (p. 5).

In considering the two worldviews, it is possible to identify some general differences between Western science and Indigenous knowledge.

In the Australian context, Aboriginal and Torres Strait Islanders have been jointly referred to as Indigenous Australians, which gives rise to the descriptor, Indigenous perspectives. 
1. Whereas Western science suggests it is universal, Indigenous knowledges are multiple and local or place-based and include location-specific knowledge, content and language. Indigenous is used here to encompass a variety of knowledges held by individual tribes or language groups according to their locality but not necessarily sharing the same content. As a consequence, the term Indigenous can be replaced by localised identifiers, e.g. Maori science, Yolngu science.

2. Although similar to each other in nature, though not necessarily in content or context, often Indigenous knowledge is homogenised and made to seem inclusive of many or all Indigenous peoples.

3. Indigenous knowledge usually refers to particular environmental and landscape knowledge and contains elements that refer to the people's relationship to the land, to its creation and its ongoing management.

4. Some Indigenous knowledge is considered particular to a group such as men only, women only, Elders or sacred and may not be shared with others.

5. Indigenous knowledge is considered holistic rather than broken into separate knowledge disciplines. Indigenous science is a Western construct of that part of Indigenous knowledge relating to Western science content and reflecting Western science's universalism rather than the Indigenous localism. The concern of some Western scientists that Indigenous knowledges may include the 'spiritual' and from this viewpoint is an issue for positivistic science ontology. The term Traditional Ecological Knowledge (TEK) is used to describe Indigenous environmental knowledge which again varies between localities.

6. The Indigenous perspectives as seen in the school curriculum are also a Western construct and their subdivision over the learning areas reflects the Western division of knowledge rather than a place-based holistic approach.

Snively and Corsiglia (2001) expressed Traditional Ecological Knowledge as how "Indigenous science interprets how the local world works through a particular cultural perspective" and "oral culture peoples may be thought of as specialists in local Indigenous science" (p.10, our emphasis). Van Eijck and Roth (2007) considered the difference between Western scientific knowledge and TEK, again identifying TEK as a local knowledge. Although they considered that the two knowledges were incommensurable and irreducible to each other, and that scientific knowledge is expressed in a universal format (e.g. language, terminology), they realised that often it needs to be related to a localised context, a feature of TEK. In discussing Aboriginal science Christie (1991) considered that "it is the context itself which provides the crucial information we are to learn" (p. 29). Invoking the environmental troupe, "Think globally, act locally', Christie considered that Indigenous local knowledge is an important factor in ecological sustainability. A number of scientists, particularly those working in ecology with Indigenous peoples in locations worldwide, have come to see the value of the two aspects as not necessarily incommensurable but having some useful compatibility (Semali \& Kincheloe, 1999). Lowan (2012) provides examples of programs in Indigenous environmental science which strengthen and advance it "for the benefit of both Indigenous and non-Indigenous peoples alike" (p. 79). Such compatible knowledge has been visualised using Venn diagrams that depict in the intersection the common ground associated with Western science and Indigenous knowledge (Michie, Anlezark \& Uibo, 1998).

\section{Mapping and Indigenous perspectives}

As already outlined, an Indigenous perspective in western school science is not based in Indigenous culture, so in the main is considered to be abstract based visible or invisible properties, whether essential or superficial (Safayeni et al., 2005). This study provides visualisations constructed as a web of associations, recognising prior knowledge, experiences and personal understandings, as it is likely that concepts of Indigenous perspectives are unfamiliar to pre-service and possibly practicing teachers of science. More specifically, the label Indigenous perspective can have implications for the teaching of science where teachers will need to engage in processes of reconceptualisation that will generate an "ongoing creation and re-creation of the web association" (Davis, Sumara \& Luce-Kapler, 2015, p.81). The reconceptualisation will require a conscious re-working of meanings constructed using the official knowledge of the Western school science curriculum. Such re-structuring of official knowledge will challenge teacher pedagogical code and practice, with modification of personal, collective and culturally 
constructed meanings of the teaching of science (Bernstein, 2000).

The pedagogical code indicates classrooms propagate knowledge and practice through distributive rules that are culturally based. These distributive rules depend on constructed recognition and realisation rules of the culture. In Bernstein's earlier work (1971) he notes that "curriculum defines what counts as valid knowledge, pedagogy defines what counts as a valid transmission of knowledge and evaluation defines what counts as a valid realisation of the knowledge on the part of what is taught" (p. 85). This statement has direct implications for the incorporation of Indigenous perspectives in teaching of science on two levels. Firstly, in Western school science codes are constructed through rules of recognition and realisation about knowledge, pedagogy, reconceptualising pedagogic practices in the teaching of school science. Secondly, in considering codes as culturally based, Indigenous perspectives are based in Indigenous cultures just as the science curriculum is based in Western cultures. It follows that through the pedagogical code, teacher recognition and realisation will evoke contexts in their pedagogical practice that are "inseparable from the concepts of illegitimate and legitimate communication, and presupposes a hierarchy in forms of communication" (Bernstein, 1990, p.15). These codes are "tacitly acquired and select and integrate relative meanings" (p.14) and "culturally determined positioning devices" (Bernstein, 1990, p.13). So, if the corollary is true that the rules of recognition and realisation define what is or is not western school science. Indigenous perspective is not based in the Western culture, so where does an Indigenous perspective fit in science classrooms?

This paper positions the purpose of the concept and mind maps as individuals' visualisations of their constructed knowledge (Kinchin, 2011). Thus, all representations are valid and may vary considerably because a particular person's knowledge about a given topic is constructed differently. Each represents its creator's personal knowledge (Cañas \& Carvalho 2004). The individual student maps represent a point-in-time construction of the students' cognitive structure as illustrations of conceptual understanding of new emergent knowledge (O'Connor, 2012). The concept and mind maps provide an externalising of Indigenous perspectives as related to a Western school science concept(s) by elicited knowledge relationships within a student's perceptual framework (Kinchin, 2011). The maps are the personal understandings and subjective interpretations of an Indigenous perspective.

\section{Network theory and mapping}

Network theory refers to the characteristics and mechanisms that interact within network structures to yield particular understandings (Borgatti \& Halgin, 2011). A network consists of a set of nodes along with a set of links between them. The links are "interconnected through shared endpoints to form paths that indirectly link nodes" (p. 1169). Concepts are considered to be nodes and the patterns in concept and mind maps are created by the links in the network. The network describes a unique structure of relationships between the nodes. These complex relationships can be better understood using mathematical modelling and visualisation.

The links constitute a binary relationship between two nodes, and one node may have many links or binary relationships with other nodes to develop a web of association. Similar situations are found in the 'family of networks' such as: knowledge networks, social networks, sematic networks, mind maps and concept maps. The links can be directional or unidirectional to represent that relationship between nodes. However, in concept maps the nodes are concepts and the links are propositions that represent a point in time cognitive model of understanding.

\section{Methodology}

Our research is a mixed methods study imbedded in pre-service teachers of science "experiences, perspectives and histories" (Lewis \& Ritchie, 2003, p. 3) of Indigenous perspective in Western school science. Firstly, we undertook a qualitative study where we considered pre-service teachers of science' perceptions of Indigenous perspective as related to a school science concept. The perceptions were presented as concept and mind map visualisations. The visualisations provided an opportunity for different ideas, mental models and prior knowledge to externalise "a complex holistic picture" (Creswell, $1998, p .15)$ represented as a knowledge network. Subsequently, the visualisations were quantitatively 
examined using network theory based mathematical modelling to uncover complex interrelationship presented in the visualisation data.

\section{Data collection}

The data in this research were collected using a concept or mind map open-ended task that provided an exploration of pre-service teachers' of science views of western school science concepts and Indigenous perspectives. The task was described as: "In this activity you will use a concept/topic from any science area (strand/outcome) and using aspects of Indigenous perspective(s), develop a concept or mind map of this concept/topic containing the Indigenous perspective(s)". Data was collected over two years from 150 students.

The concept and mind maps were initially examined by the two researchers using a number of criteria, including Indigenous perspectives, science links, number of subtopics in the first tier, hierarchy (or morphology), illustrations and relationships.

\section{Results}

The first aspect of the results centres the morphology of the concept and mind maps. Morphology describes the shape of the visualisations and reflects the level of complexity of understanding of the constructor. The complexity of representation can be demonstrated in the frequency of the type of concept map morphology, as presented in Table 1. As indicated in Table 1, the majority of students (80.6\%) used network and repeated spoke morphologies in preparing their visualisations.

Table 1: Frequency of visualisation morphology

\begin{tabular}{|l|c|c|}
\hline Type of concept map & Total & Percent \\
\hline 1. Chain & 1 & 0.7 \\
\hline 2a. Basic spoke & 5 & 3.4 \\
\hline 2b. Spoke with chains & 23 & 15.3 \\
\hline 2c. Repeated spokes & 98 & 65.3 \\
\hline 3. Network & 23 & 15.3 \\
\hline
\end{tabular}

The complexity of the concept maps impressed the researchers, particularly considering students have presented sophisticated morphologies: network and the repeated spokes. We concur with Kinchin (2011) that "networks are associated with meaningful learning" (p. 99). These students indicated a depth of knowledge regarding Indigenous perspectives that exceeded our expectations and the networks reflected the interrelatedness which is a feature of Indigenous knowledge (Semali \& Kincheloe, 1999). However, we disagree with Kinchin (2011) regarding spokes, particularly repeated spokes. He considered spokes as offering limited insight which may be the case in their basic forms, whereas in their repeated morphology they provide a deeper understanding although not as complex or interrelated as a network.

The emergent knowledge presented in the concept map below (Figure 1) presents a complex view of weather and seasons. This visualisation was considered by both researchers to be the most complex example. It demonstrates the complex relationship between patterns, seasons, plants, animals, symbols and stories, with specific reference to an Indigenous language group. Its morphology is a network, exemplified by cross links at a number of levels and between levels, and is considered to be handdrafted. The graphics that were used were also selected by the student.

The mind map (Figure 2) demonstrates a complex understanding using repeated spoke morphology relating to Aboriginal Astronomy. This depiction of Aboriginal Astronomy links together sun, moon, planets and stars through story and legend.

These two examples presented are but a few of the 150 visualisations that demonstrate a 'point in time' interrelated conceptual representation of Western school science topics from the ACS content descriptions and Indigenous knowledge. 
Figure 1: Seasons and Weather Concept Map, using network morphology

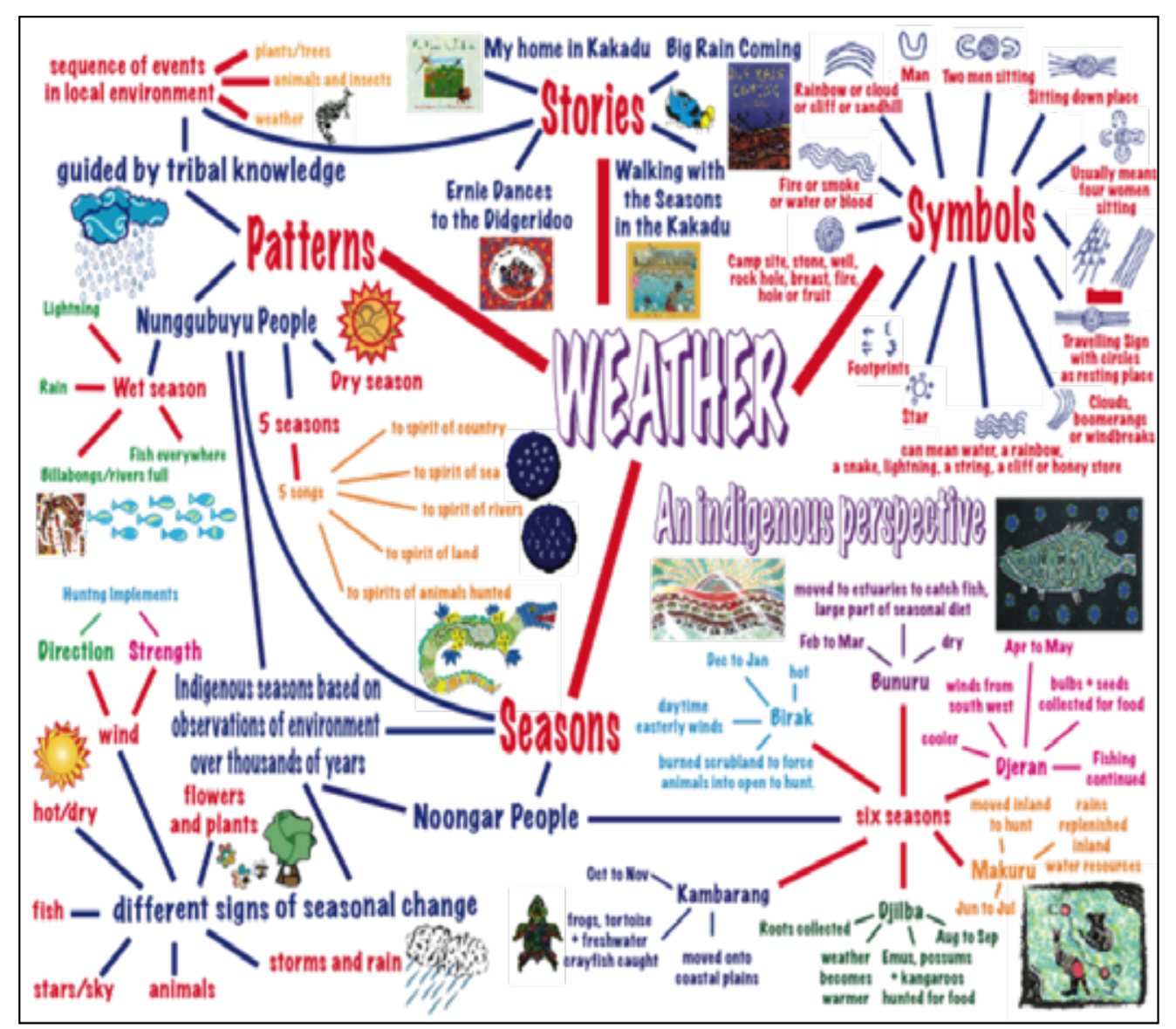

Figure 2: Aboriginal Astronomy Mind Map, using repeated spokes morphology

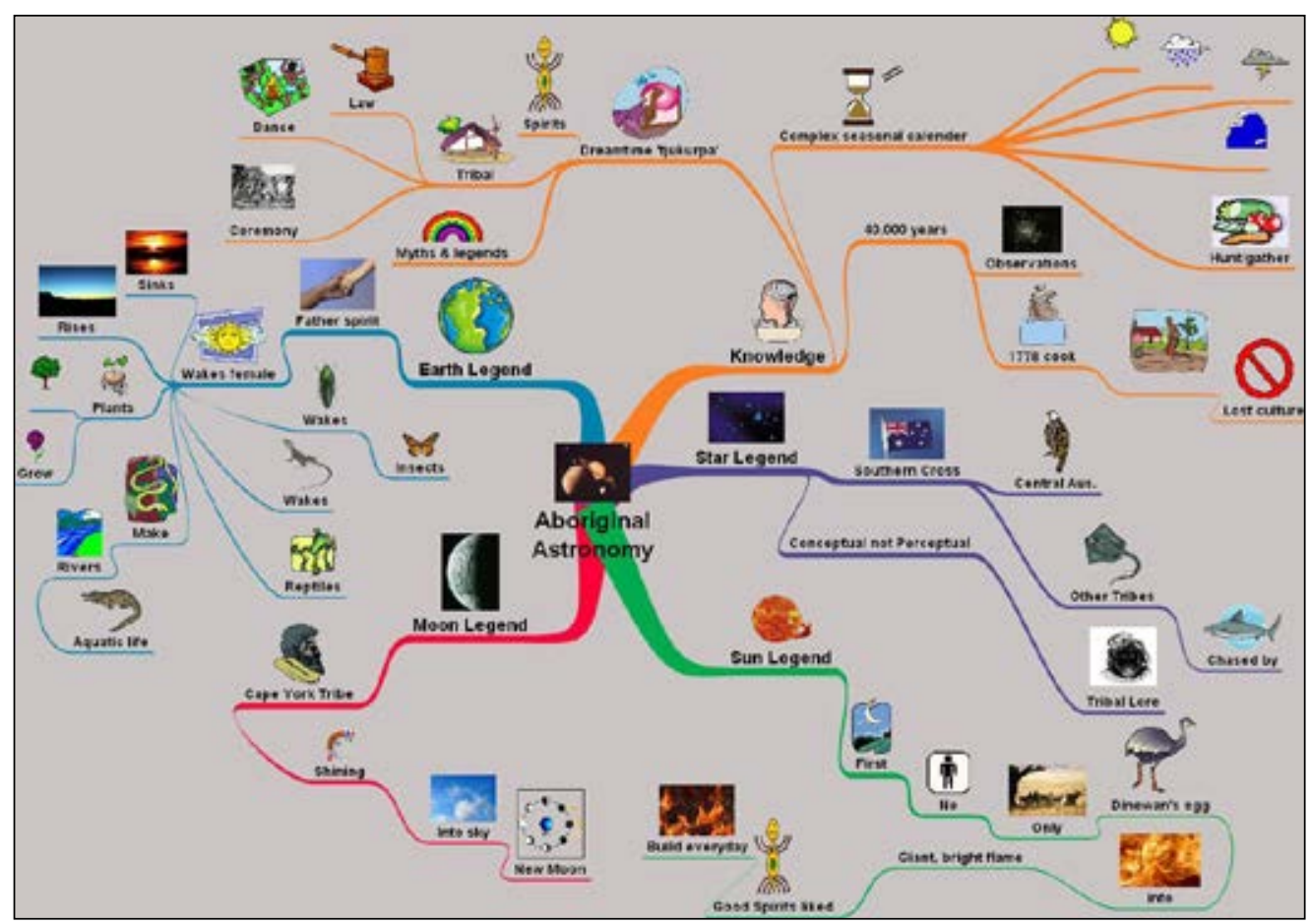




\section{Analysis}

The 150 participants in the open-ended task presented individually-constructed visualisation depicting their understanding of the relationship between a science concept and Indigenous perspectives. The visualisations were analysed, with the understanding that the methodology enables the presentation of a diverse number of student perspectives. The analysis provided an opportunity to develop a shared conceptual framework that represented shared meaning while preserving the individuality and diversity (Trochim \& Cabrera, 2005). The analysis progressed through three stages to ensure the preservation of the relational structures of the visualisations. The relational structures refer to the centrality of concepts, number of links, density of connections and inter-category links theoretically grounded in network theory (Stautmane, 2012).

The following analysis is presented in three levels: identification of central Western school science themes, Western school science themes network analysis and meta-network analysis.

\section{Level 1: Identification of central Western school science themes}

In level 1, using the central concepts in each visualisation, a process of identification and categorisation was used by the researchers to identify central science themes. The visualisations were then grouped. This initial analysis uncovered six school science themes: Seasons and Weather, Astronomy, Ecology, Plants, Animals and Use of Natural Resources (Table 2). These are the terms used in the ACS (ACARA, 2015). The category 'Others' were rejected as they did not meet the task requirements.

Table 2: Frequency of school science themes.

\begin{tabular}{|l|c|c|}
\hline School science theme & Number & Percentage \\
\hline Use of Natural Resources & 44 & 29.4 \\
\hline Seasons and Weather & 37 & 24.7 \\
\hline Ecology & 28 & 18.6 \\
\hline Animals & 12 & 8.0 \\
\hline Astronomy & 11 & 7.3 \\
\hline Plants & 9 & 6.0 \\
\hline Others & 9 & 6.0 \\
\hline
\end{tabular}

\section{Level 2: School science themes network analysis}

\section{Stage 1: Identification of concepts.}

The six themes having been identified were analysed to determine the scope and range of the concepts that were presented in each of the school science themes. This was achieved firstly by using the word cloud approach to provide a frequency visual presentation of the terms for each of the identified science themes. An example using the theme Seasons and Weather is presented in Figure 3. 
Figure 3: Seasons and Weather word cloud

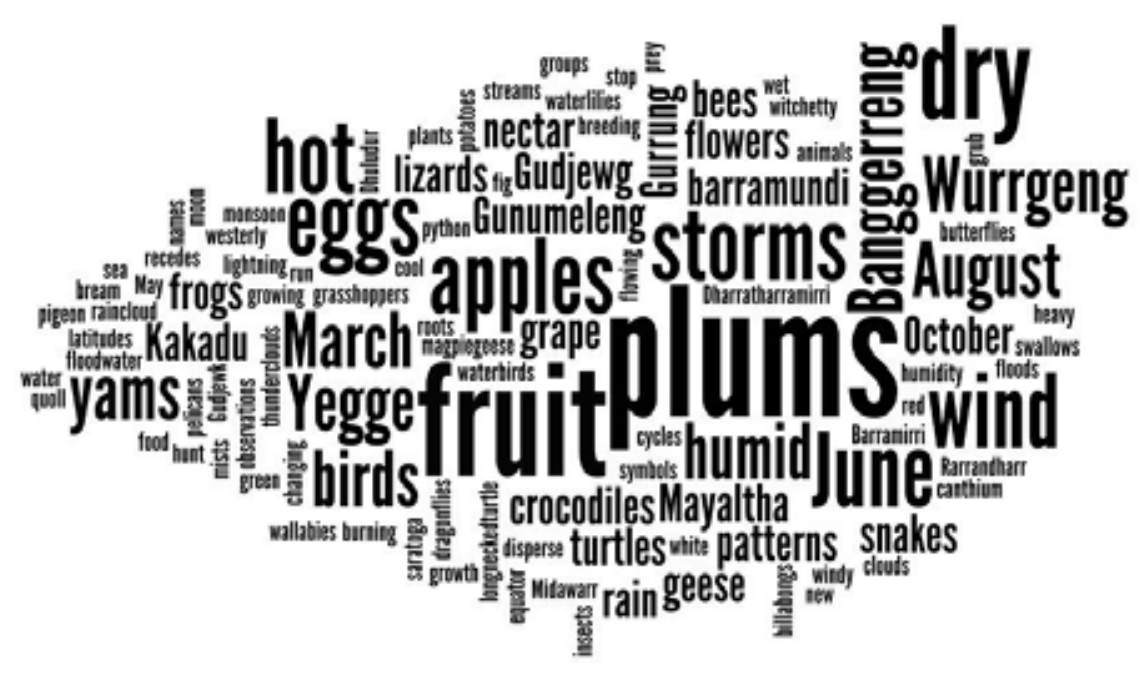

This word cloud provided representation of the concepts and frequency present in the Season and Weather theme. A scan of the terms presents a diversity of terms the used to represent seasons and weather. They included plants and animals with specific examples; Indigenous and Western season names; and weather related activity for example storms and humidity. However, this approach did not recognise the interrelationships: 'what is connected to what' aspect within the visualisations, within a theme or across all themes. A network based approach was used in identifying the relational links between concepts found in individual concept maps across each identified theme.

\section{Stage 2: Concept-concept links}

In stage 2 each school science theme was analysed using a statistical network package called ORANetScenes. ORA-NetScenes is a dynamic meta-network assessment and analysis tool developed by the Centre of Computational Analysis of Social and Organisation Systems (CASOS) at Carnegie Mellon University. This package is based on the principles of network theory and mathematical modelling that recognises nodes, maintains links and generates network visualisations (Carley, Pfeffer, Reminga \& Storrick, 2013).

Each of the school science themes was analysed using ORA. Firstly, this process required the concepts and the link relationships to be aggregated and converted into an Adjacent Matrix. The matrix is a square concept-by-concept ( $\mathrm{i}=\mathrm{j})$ matrix where the presence of a dyadic pair links are recorded as a ' 1 ' and ' 0 ' no link. This process of aggregation and maintenance of the concept-concept link representations was completed for each science theme, and the resultant dyadic pairs then saved as CSV files for further analysis using ORA. This process produced six matrices, one for each science theme. Each matrix indicates a concept-concept relationship for that theme. It is at this stage the ORA statistical package was used to visualise the matrix, while maintaining the concept-concept dyads.

The network theme matrices were analysed individually to develop network visualisations and the statistical metric of centrality. Centrality in this analysis presents a measure of the connectedness of the nodes, such that the nodes that are ranked high on this metric have more connections to others in the same network. Two values are calculated by the software, an unscaled value which is simply the number of connections between concepts, and a relative value of comparison for all nodes in the network (maximum value=1). The choice of centrality provides an opportunity to identify the most important nodes within the network (Everett \& Borgatti, 2005).

Seasons and Weather network (Figure 4) is an example of a generated network visualisation, a result of the ORA analysis and visualisation. This process was repeated for all the school science themes to generate six network diagrams. 
Figure 4: Seasons and Weather network

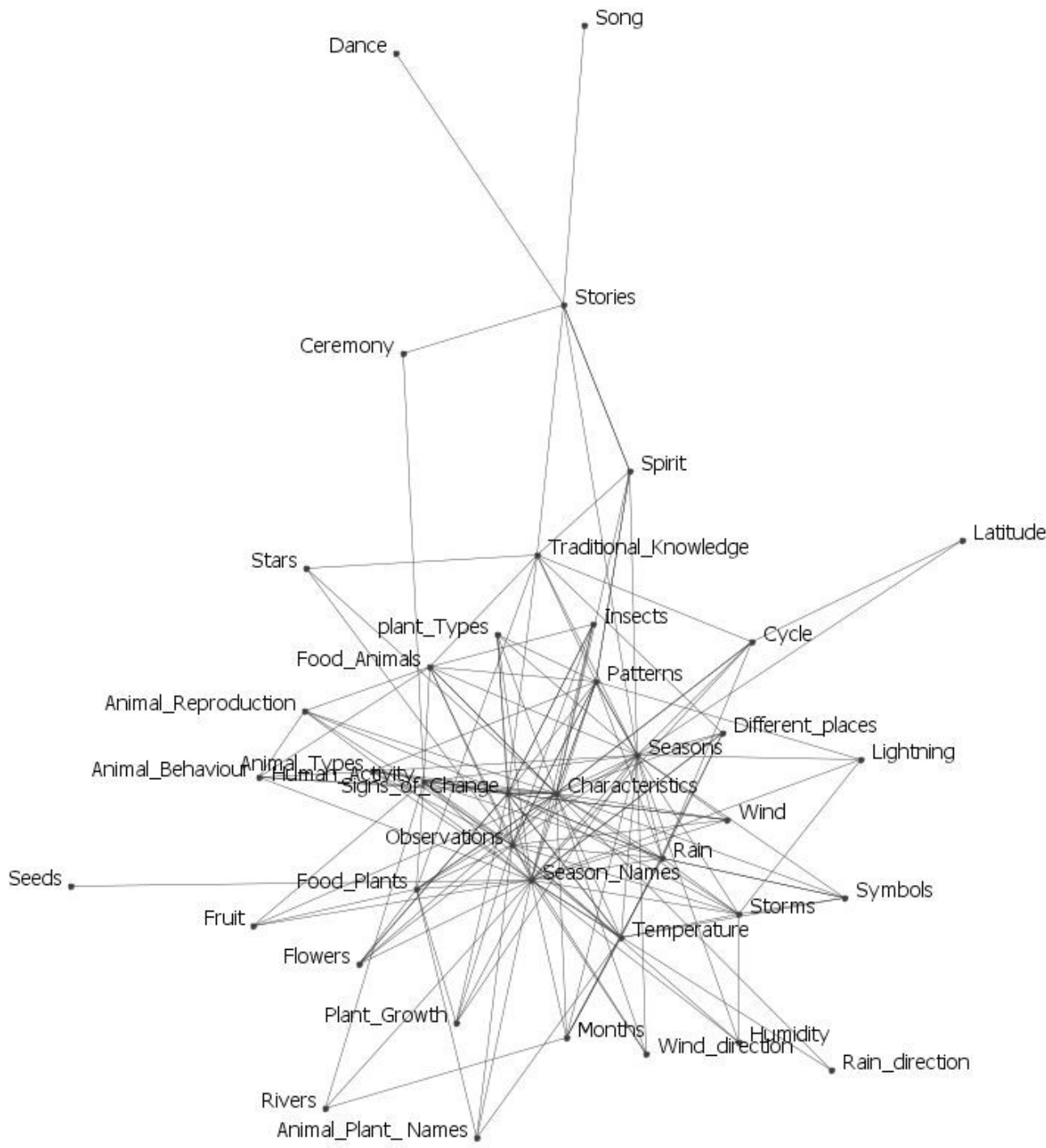

The network visualisation for Seasons and Weather (Figure 4) presents the 43 node entities, where the nodes with high centrality values tend to be in the centre of the network. Other nodes with few links are located towards the periphery; the measures of centrality reflect this finding.

In the Seasons and Weather network, the top five centrality ranked nodes at first glance present neither Indigenous nor Western school science perspectives, as seen in Table 3. However, in cross-referencing with the word cloud for Seasons and Weather (Figure 3) there was extensive use of Indigenous season names in the student's original concept maps. The combination of Indigenous and season names into the label 'season names' was done to manage the matrix size. The use of the term 'season names' can represent use of both Indigenous season names and Western season names. The two most connected concepts are season names and characteristics (relative values of 0.131 and 0.127 respectively, with 33 and 32 links each). In considering the next five ranked nodes - patterns, rain, human activity, temperature and food animals - there are some indications of a mixture of Western and Indigenous perspectives or knowledge. 
Table 3: Seasons and Weather centrality

\begin{tabular}{|c|l|c|c|}
\hline Rank & Central Concepts & Centrality & Number of links \\
\hline 1 & season names & 0.131 & 33 \\
\hline 2 & characteristics & 0.127 & 32 \\
\hline 3 & seasons & 0.107 & 27 \\
\hline 4 & signs of change & 0.095 & 24 \\
\hline 5 & observations & 0.091 & 23 \\
\hline
\end{tabular}

The network (Figure 4) presents a decentralised network visualisation of the interconnectedness and is the key to understanding the pre-service teacher of science interpretations of Indigenous perspectives and Western school science. Put another way, we know the most connected concepts (centrality or central concepts), but the question remains: What are these central concepts connected to? The answer comes from following the links in the visualisation. So, these connections through the network paths provide an emergent representation of seasons and weather as an Indigenous perspective.

The centrality data (Table 3 ) indicates that the five central concepts have total link numbers ranging from 33 to 23; these include multiple links. Analysing the network paths from the most central concepts presents an opportunity to construct an emergent picture of science education student perspectives of Western school science and Indigenous perspectives. For example, the central concept of 'signs of change' demonstrates linkages (network path links) within the network (Table 4). The network path links suggest that the theme of seasons and weather, as an Indigenous perspective is something more than looking at weather maps, measuring the temperature and rainfall².

Table 4: Signs of change links

\begin{tabular}{|l|l|}
\hline Central Concept & Network Path Links \\
\hline Signs of change & $\begin{array}{l}\text { Animal types, temperature, animal reproduction, rain, wind, plant } \\
\text { types, storms, characteristics, patterns, traditional knowledge, season } \\
\text { names, plant growth, insects, rain, human activity, observations, animal } \\
\text { behaviour, flowers, animals, food }\end{array}$ \\
\hline
\end{tabular}

To further investigate the interrelationships between the science presented in the Western school curriculum and Indigenous perspectives, a science theme centrality comparison (Table 5) was developed. The comparison uses the top 10 ranked centrality nodes from each of the six science themes.

2 The other five themes were analysed using the same methodology. These have been omitted here; however the authors are willing to share these visualisations. 
Table 5: Science theme centrality comparison

\begin{tabular}{|c|c|c|c|c|c|}
\hline \multicolumn{6}{|c|}{ Theme Networks } \\
\hline Astronomy & Ecology & Plants & $\begin{array}{c}\text { Seasons \& } \\
\text { Weather }\end{array}$ & $\begin{array}{l}\text { Use of Nat. } \\
\text { Resources }\end{array}$ & Animals \\
\hline beliefs & land & food & season name & food & animals \\
\hline patterns & animals & medicine & characteristics & animals & hunting \\
\hline stars & habitat & seasons & seasons & plants & food \\
\hline moon & $\begin{array}{c}\text { land } \\
\text { management }\end{array}$ & trees & $\begin{array}{l}\text { signs of } \\
\text { change }\end{array}$ & medicine & insects \\
\hline sun & environment & preparation & observations & hunting & ceremony \\
\hline relationships & stories & administrating & patterns & $\begin{array}{c}\text { land } \\
\text { management }\end{array}$ & dreaming \\
\hline seasons & ceremony & leaves & rain & seasons & skins \\
\hline stories & diversity & seeds & human activity & fire & fire \\
\hline dreaming & food & gathering & temperature & gathering & art \\
\hline food & art & eucalyptus & food animals & kangaroo & kangaroo \\
\hline
\end{tabular}

This table presents a number of the terms/concepts that are repeated in two or more of the themes. These are indicated in bold and italics are used to highlight the terms considered to be potential Indigenous knowledge. The comparison of the identified centrality measured top 10 concepts and terms indicates interrelatedness across the science themes. This interrelatedness is further investigated as a meta-network.

\section{Stage 3: Meta-network visualisation}

A meta-network is defined as a representation of a group of networks (Carley et al., 2013) that aggregates all node links from the identified six school science themes into one network: the meta-network. Visually this is a very complex and is not presented here, however the centralities represented in the metanetwork were also calculated and are displayed in Table 6. 
Table 6: Meta-network centrality

\begin{tabular}{|c|c|c|}
\hline Rank & Concept & Centrality \\
\hline 1 & Food & 0.059 \\
\hline 2 & Seasons & 0.053 \\
\hline 3 & Animals & 0.053 \\
\hline 4 & Land & 0.030 \\
\hline 5 & Ceremony & 0.029 \\
\hline 6 & Stories & 0.026 \\
\hline 7 & Dreaming & 0.023 \\
\hline 7 & Land management & 0.023 \\
\hline 7 & Plants & 0.023 \\
\hline 8 & Fire & 0.022 \\
\hline 9 & Art & 0.021 \\
\hline 10 & Medicine & 0.020 \\
\hline
\end{tabular}

The centrality here indicates a high level of interconnectedness between many nodes, some of which are inclusive of Western and Indigenous knowledge while others are exclusively Indigenous. This interconnectedness would suggest that an Indigenous perspective from the pre-service teacher perspective is a network of Indigenous and Western school science curriculum knowledge.

To further investigate this claim the meta-network was reduced in complexity by developing a 'sphere of influence' visualisation constructed from the five most central concepts from each theme. Everett and Borgatti (2005) validates this approach by suggesting that centrality is a local property in a network, and within a sphere of influence network the centrality is the same as the network. The sphere of influence network visualisation for the meta-network is represented in Figure 5.

Figure 5: Sphere of influence network

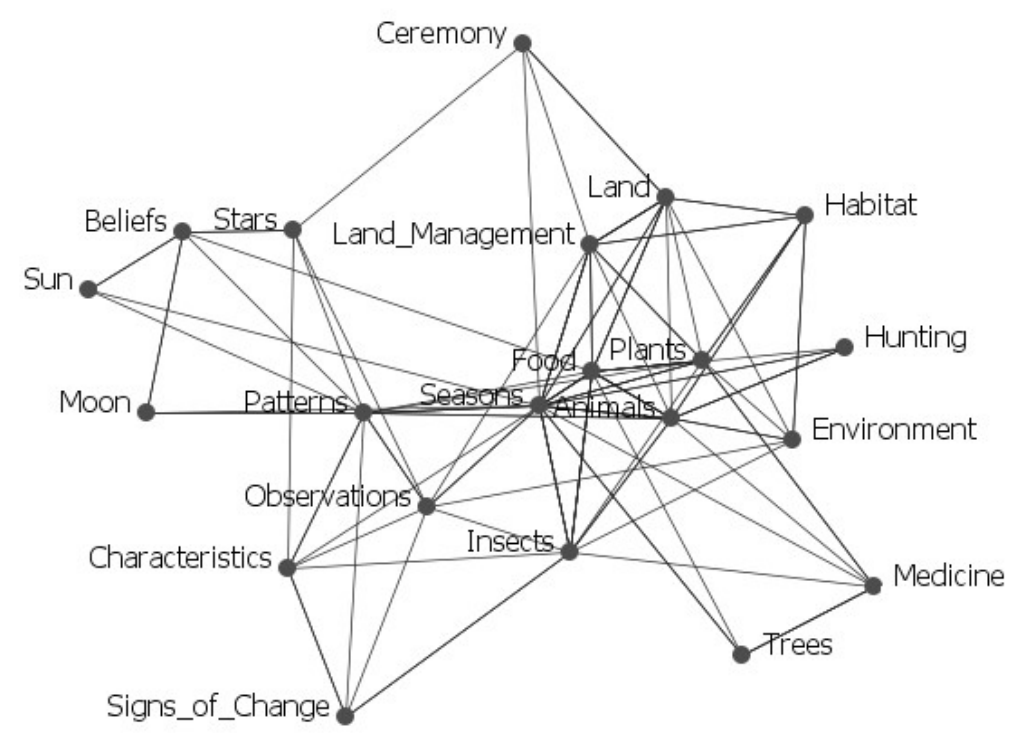

This representation reinforces the notions of interrelatedness between the Western school science and Indigenous knowledge. 


\section{Discussion}

The student visualisations have demonstrated complex interrelationships between school science and Indigenous perspectives through the six school science themes: Seasons and Weather, Astronomy, Ecology, Plants, Animals and Use of Natural Resources. Network analysis of the school science themes demonstrates these six themes are interrelated within and between themes. The interrelationship presented by the pre-service students indicates a strong interdisciplinary sense of aspects of the school science curriculum.

The Australian Curriculum: Science (ACS) presents content as Science as Understanding in four substrands: Biological, Chemical, Earth and Space, and Physical Sciences (ACARA, 2015). The content is then dissected by year level. Another strand of ACS describes Science as a Human Endeavour.

The Seasons and Weather network represents a system approach, where plants, animals, Indigenous knowledge and human activities are linked to characteristics, patterns, signs of change and observations. The network analysis brings together Biological Sciences (with its focus in living things and the environment: external features, growth, life cycles, structural features, physical conditions) and Earth and Space Sciences (with the concept of change - daily, weather, seasonal - observable over time on land and in the sky). The linking presents a decentralised network of interconnected concepts that join together the Science as Understanding sub-strands of Earth and Space Science and Biological Science into a relational view of the world that provides pedagogical space for interactions across the sub-strand boundaries. This pattern is repeated across the other five theme networks. In addition, in Chemical Sciences, natural and processed materials and physical and chemical changes are represented across Plants, Animals, Use of Natural Resources and Ecology networks.

The themes also represent a view of Western school science as Science as a Human Endeavour (ACARA, 2015), where the students' understanding of science and Indigenous perspectives seeks to 'improve their understanding and explanations of the natural world'. The emergent networks derived from the pre-service teachers of science, demonstrate a conceptualisation of the natural world as connection between the disciplines based knowledge of science, the physical world, the human world and a sacred world of Indigenous ways of knowing and being.

The meta-network constructed from all the themes presents a decentralised relational knowledge visualisation that makes no distinctions between the disciplines based knowledge of western school science, the physical world, the human world and a sacred world. The premise of Indigenous perspectives as relational knowledge was tested through the sphere of influence. This visualisation again reinforced notions of connectivity through a decentralised network.

In considering space science, as an example, the ACS content descriptions (ACARA, 2015) present space science as observable changes in the sky, Earth's rotation causing regular changes, predictable phenomena on Earth, including seasons and eclipses, are caused by the relative positions of the sun, Earth and the moon. However, the analysis would suggest a wider conception space science that includes Biological and Earth sciences where the sun, moon and stars linked to beliefs, patterns, characteristics and change with recognition of the centrality of ceremony, land, human activity, seasons and food, plants and animals. The two representations are not diametrically opposed, but intertwined through notions of human endeavour.

The depiction of this aspect of the meta-network suggests a more holistic interdisciplinary view of the natural world. What is clear is that students' perceptions present a decentralised knowledge network that links school science concepts, Indigenous knowledge and culture.

The ACS presents pre-service science education students with compartmentalised curricula and maintains the reductionist view of knowledge of science. There is however, a space that develops in the current curriculum that allows pre-service students and teachers to consider the relationships between the moon, sun, beliefs, seasons, insects and medicine, as evident in the sphere of influence network. This space is the 'overarching ideas'.

The overarching ideas of science as presented in the ACS (ACARA, 2015) are key aspects of a scientific view of the world that bridge knowledge and understanding across the disciplines of science. There 
are six of these ideas: patterns, order and organisation; form and function; stability and change; scale and measurement; matter and energy; and systems. The notions of bridging knowledge across the science disciplines provide a space for pre-service and practicing science teachers to reconceptualise the official knowledge in the school science curriculum and so the possibility of validating a holistic view of discipline-based knowledge of science, the physical world, the human world and a sacred world of Indigenous knowledge.

The six theme networks and the meta-network constructed from student concept maps present an interconnected approach to curriculum. Where knowledge is connected in 'not so clear' boundaries between school science and Indigenous knowledge is evident. This system of interconnections can be exemplified by examples from the meta-network, for example; between insects and seasons there are links, but the path links also connect with medicine, environment and animals. Such path links, from a pre-service student perspective indicate a direct association between these concepts/knowledge or more broadly earth science, biology and ecology to use a reductionist view. This research presents concepts and knowledges as a part of a connected curriculum system that provides for a more holistic view of the school science curriculum.

The overarching idea of patterns, order and organisation, stability and change along with the fundamental science principles of observations, patterns, characteristics and signs of change are strongly represented in the links demonstrated by the pre-service students. The students present a relationship between Indigenous knowledge and school science based in a borderless intercultural view of the world. The research indicates that concepts like observation, patterns and signs of change are not the prerogative of reductionist school science, but are a more systemic holistic principle of the human engagement with the world.

What is also recognised is that the themes relate to the human endeavour and place in the world where local contexts, knowledge of place provide an over-arching link to the world. This is in contrast to the universality attributed to science knowledge presented in the current science curriculum. The relationships uncovered in this research develop a holistic focus that presents an interpretation of how the world is relational and more particularly, how the local world can be understood.

\section{Conclusion: understanding of Indigenous perspectives}

Examination of the networks developed from the pre-service teachers of science provided us with a refreshing view of the students' understandings. Some of the visualisations provided complex and sophisticated Indigenous perspectives, nuanced through the structure of the visualisation itself. Students apparently considered Indigenous perspectives beyond the stereotypes encountered previously (e.g. Ninnes, 2000), as exemplified by the measures of centrality and high levels of linkage between the six themes that bring a richness of connectivity to Western school science knowledge with concepts of Indigenous knowledge and culture.

That the students identified only six areas of school science is not considered a limitation but rather the realisation that Indigenous perspectives in the science curriculum do not apply across all content description. There are content descriptions where Indigenous knowledge can and should be examined, and that it should not be tokenised or stereotyped through attempts to be forcibly integrated, a situation also recognised by Aikenhead et al. (2014). What is notable is that the topics chosen related to the local and every day: place-based knowledge, rather than universalised Western school science topics. Also, there was no engagement with the stereotypical physics topics such as gyroscopes and boomerangs, or levers and spear-throwers.

There is little evidence that the pre-service teachers of science education have taken a 'two disparate' worldview position that has been previously outlined. Some students did present their visualisations as a binary school science and Indigenous knowledge perspective. However, the majority of the students perceived an Indigenous perspective in science education as an interrelated human endeavour interacting with the natural world where the two worldviews coexist with one informing the other. 


\section{References}

ACARA. (2011). Australian Curriculum. Australian Curriculum, Assessment and Reporting Authority.

ACARA. (2015). Australian Curriculum: Science F-10. Version 8.2. Australian Curriculum, Assessment and Reporting Authority.

Aikenhead, G. (1996). Science education: Border crossing into the subculture of science. Studies in Science Education, 27, 1-52.

Aikenhead, G. (2001). Students' ease in crossing cultural borders into school science. Science Education, 85, 180-188.

Aikenhead, G., \& Jegede, O. (1999). Cross-cultural science education: A cognitive explanation of a cultural phenomenon. Journal of Research in Science Teaching, 36, 269-287.

Aikenhead, G., \& Ogawa, M. (2007). Indigenous knowledge and science revisited. Cultural Studies of Science Education, 2, 539-591.

Aikenhead, G., Brokofsky, J., Bodnar, T., Clark, C., Foley, C., Hingley, J., Isbister, D., Johanson, T., Lauze, C., Myers, S., Roadhouse, T., Rioux, T., Speidel, D., Speidel, W.D., \& Strange, G. (2014). Enhancing school science with Indigenous knowledge: What we know from teachers and research. Saskatoon, Saskatchewan: Saskatoon Public School Division.

Bernstein, B. (1971). Knowledge and control. London: Collier Macmillan.

Bernstein, B. (1990). The structure of pedagogical discourse: Class, codes and control, Vol IV. London: Routledge.

Bernstein, B. (2000). Pedagogy, symbolic control and identity: Theory, research, critique. Oxford: Rowman and Littlefield.

Borgatti, S. \& Halgin, S. (2011). On network theory. Organization Science. 22(5), 1168-1181.

Bradley, D., Noonan, P. Nugent, H., \& Scales, B. (2008). Review of Australian Higher Education. Commonwealth Department of Education, Employment and Workplace Relations. Canberra: Commonwealth of Australia.

Bull, R. (2008). Small study - big success story. Primary Connections incorporating indigenous perspectives pilot study report. Canberra: Australian Academy of Science.

Cañas, A. (2003). A summary of the literature pertaining to the use of concept mapping techniques and technologies for education and performance support. Florida: Institute for Human and Machine Cognition.

Cañas, A., \& Carvalho, M. (2004). Concept maps and Al: An unlikely marriage. In Proceedings of Brazilian Symposium on Computers in Education (SBIE), (1), 1-10, Brazil.

Carley, K. Pfeffer, J. Reminga, J. \& Storrick, J. (2013). ORA user's guide 2013. Pittsburgh: CarnegieMellon University.

Christie, M. (1991). Aboriginal science for the ecologically sustainable future. Australian Science Teachers Journal, 37(1), 26-31.

Creswell, J. (1998). Qualitative inquiry and research design: Choosing among five methods. Thousand Oakes, CA: Sage.

Davis, B., Sumara, D., \& Luce-Kapler, R. (2015). Engaging minds: Cultures of education and practices of teaching. London: Routledge.

Everett, M., \& Borgatti, S. (2005). Extending Centrality. In Carrington, P., Scott, J., \& Wasserman, S. (Eds). Models and methods in social network analysis, New York: Cambridge University Press. 
Inspiring Australia. (2013). Indigenous Engagement with Science: towards a better understanding. Canberra: Questacon.

Kinchin, I.M. (2011). Concept mapping and the fundamental problem of moving between knowledge structures. Journal for Educators, Teachers and Trainers, 4(1), 97-106.

Kinchin, I.M., Hay, D.B., \& Adams, A. (2000). How a qualitative approach to concept map analysis can be used to aid learning by illustrating patterns of conceptual development. Education Research, 42(1), 43-57.

Lewis, J., \& Ritchie, J. (2003). Generalising from qualitative research. Qualitative research practice: A guide for social science students and researchers, 263-286.

Lowan, G. (2012). Expanding the conversation: further explorations into Indigenous environmental science education theory, research, and practice. Cultural Studies of Science Education, 7(1), 71-81.

Matthews, M.R. (Ed.). (2009). Science, worldviews and education (pp.1-26). Dordrecht: Springer.

MCEECDYA. (1989). The Hobart Declaration on Schooling. Ministerial Council for Education, Early Childhood Development and Youth Affairs. Retrieved from http://www.mceecdya.edu.au/ mceecdya/hobart_declaration, 11577.html.

McPhan, G. (2008). A developmental framework for assessing concept maps. In Cañas, A.J., Reiska, P., Åhlberg, M., \& Novak, J.D. (Eds.), Concept mapping: Connecting educators. Proceedings of the Third International Conference on Concept Mapping, Tallinn, Estonia and Helsinki, Finland.

Michie, M. (2002). Why Indigenous science should be included in the school science curriculum. Australian Science Teachers' Journal, 48(2), 36-40.

Michie, M. (2015). Science curricula and indigenous knowledge. In R. Gunstone (Ed.), Encyclopedia of Science Education (pp.871-877). Dordrecht: Springer Publishers. doi 10.1007/978-94-007-6165-0_312-2.

Michie, M., Anlezark, J., \& Uibo, D. (1998). Beyond bush tucker: Implementing Indigenous perspectives through the science curriculum. CONASTA 47 Proceedings. Science Teachers Association of the NT Journal, 18, 101-110.

National Curriculum Board. (2009). Shape of the Australian Curriculum: Science. Canberra: Commonwealth of Australia.

Nesbit, J.C., \& Adesope, O.O. (2006). Learning with concept and knowledge maps: A meta-analysis. Review of Educational Research, 76(3), 413-448.

Ninnes, P. (2000). Representations of Indigenous knowledges in science textbooks in Canada and Australia. International Journal of Science Education, 22(6), 603-617.

Novak, J., \& Cañas, A. (2007). Theoretical origins of concept maps, how to construct them, and uses in education. Reflecting Education, 3(1), 29-42.

Novak, J., \& Gowin, D. (1984). Learning how to learn. Cambridge University Press.

O'Connor, M. (2012). Theoretical consideration of the effectiveness of concept mapping in interpretive sense making research. In Cañas, A., Novak, J. \& Vanhear, J. (Eds), Concept Map: Theory, Methodology, Technology. Proc. of the Fifth International Conference on Concept mapping. Malta.

O'Donnell, A., Dansereau, D., \& Hall, R. (2002). Knowledge maps as scaffolds for cognitive processing. Educational Psychology Review, 14(1), 71-86.

Ruiz-Primo, M.A., \& Shavelson, R.J. (1996). Problems and issues in the use of concept maps in science assessment. Journal of Research in Science Teaching, 33(6), 569-600. 
Safayeni, F., Derbeniseva, N., \& Cañas, A.J. (2005). A theoretical note on concepts and the need for cyclic concept maps. Journal of Research in Science Education, 42(7), 741-766.

Semali, L.M., \& Kincheloe, J.L. (Eds.) (1999). What is Indigenous knowledge? Voices from the academy. New York: Falmer Press.

Snively, G., \& Corsiglia, J. (2001). Discovering indigenous science: Implications for science education. Science Education, 85(1), 6-34.

Strautmane, M. (2012). Concept map-based knowledge assessment tasks and their scoring criteria: An overview. In Cañas, A., Novak, J., \& Vanhear, J. (Eds.), Concept map: Theory, methodology, technology (Proceedings of the Fifth International Conference on Concept Mapping, I), pp.1-88, Malta.

Trochim, W. \& Cabrera, D. (2005). The complexity of concept mapping for policy analysis. Emergence, Complexity \& Organization, $7(1), 11-22$.

van Eijck, M., \& Roth, W.-M. (2007). Keeping the local local: Recalibrating the status of science and traditional ecological knowledge (TEK) in education. Science Education, 91, 926-947.

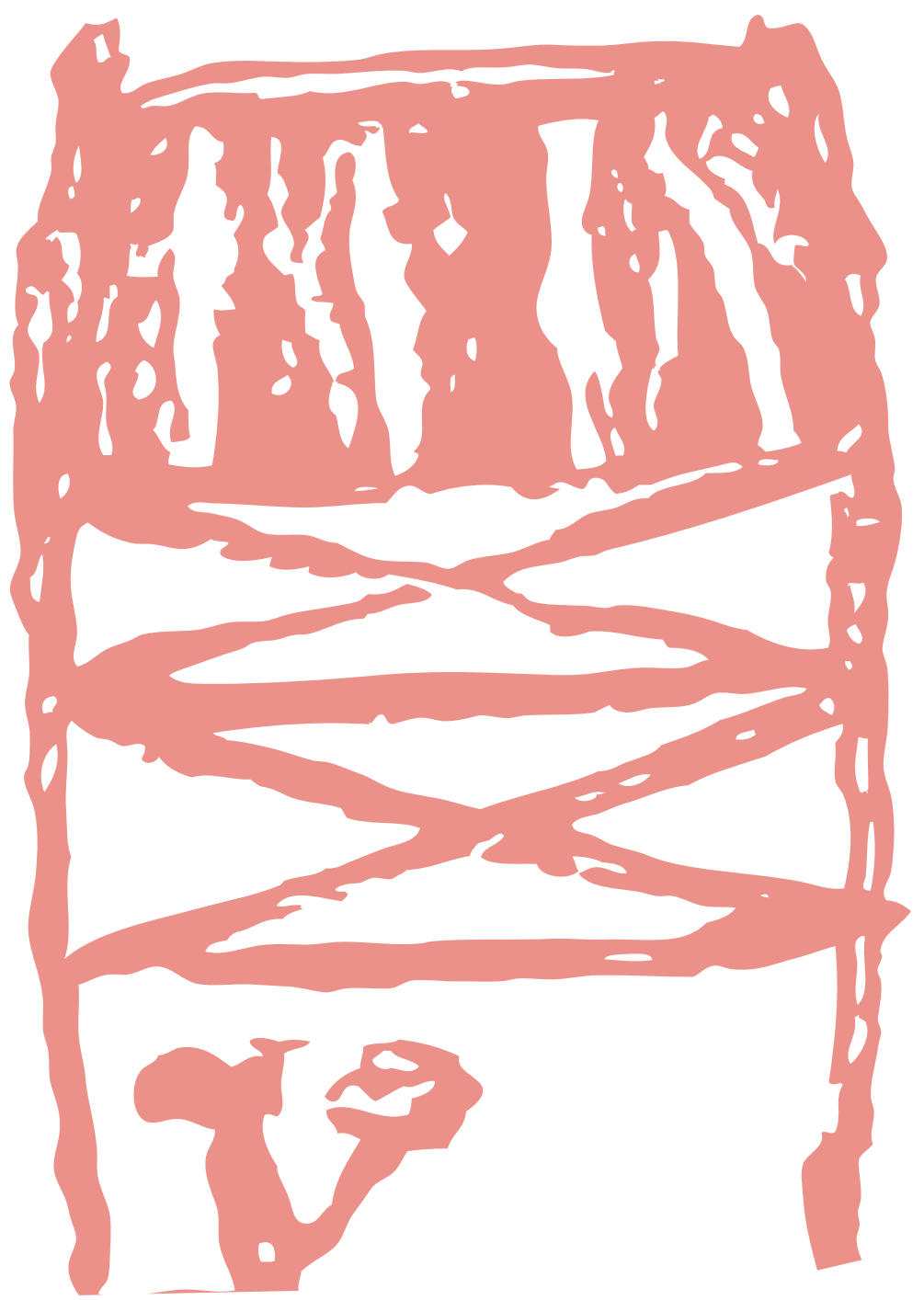

